Research paper

\title{
European spruce bark beetle (Ips typographus, L.) green attack affects foliar reflectance and biochemical properties
}

\author{
Haidi Abdullah $^{\mathrm{a}, \mathrm{b}, *}$, Roshanak Darvishzadeh ${ }^{\mathrm{a}}$, Andrew K. Skidmore ${ }^{\mathrm{a}, \mathrm{c}}$, Thomas A. Groen ${ }^{\mathrm{a}}$, \\ Marco Heurich $^{\mathrm{d}}$ \\ a Faculty of Geo-Information Science and Earth Observation (ITC), University of Twente, P.O. Box 217, 7500 AE Enschede, The Netherlands \\ b Department of Geography, College of Arts, Salahaddin University-Erbil, Kurdistan Region, Iraq \\ c Department of Environmental Science, Macquarie University, NSW, 2109, Australia \\ d Bavarian Forest National Park, Freyunger Straße 2, 94481 Grafenau, Germany
}

\section{A R T I C L E I N F O}

\section{Keywords:}

Bark beetle (Ips typographus, L.)

Green attack

Norway spruce

Hyperspectral

Foliar chlorophyll and nitrogen concentration

\begin{abstract}
A B S T R A C T
The European spruce bark beetle Ips typographus, L. (hereafter bark beetle), causes major economic loss to the forest industry in Europe, especially in Norway Spruce (Picea abies). To minimise economic loss and preclude a mass outbreak, early detection of bark beetle infestation (so-called "green attack" stage - a period at which trees are yet to show visual signs of infestation stress) is, therefore, a crucial step in the management of Norway spruce stands. It is expected that a bark beetle infestation at the green attack stage affects a tree's physiological and chemical status. However, the concurrent effect on key foliar biochemical such as foliar nitrogen and chlorophyll as well as spectral responses are not well documented in the literature. Therefore, in this study, the early detection of bark beetle green attacks is investigated by examining foliar biochemical and spectral properties (400-2000 nm). We also assessed whether bark beetle infestation affects the estimation accuracy of foliar biochemicals. An extensive field survey was conducted in the Bavarian Forest National Park (BFNP), Germany, in the early summer of 2015 to collect leaf samples from 120 healthy and green attacked trees. The spectra of the leaf samples were measured using an ASD FieldSpec3 equipped with an integrating sphere. Significant differences $(p<0.05)$ between healthy and infested needle samples were found in the mean reflectance spectra, with the most pronounced differences being observed in the NIR and SWIR regions between 730 and $1370 \mathrm{~nm}$. Furthermore, significant differences $(\mathrm{p}<0.05)$ were found in the biochemical compositions (chlorophyll and nitrogen concentration) of healthy versus green attacked samples. Our results further demonstrate that the estimation accuracy of foliar chlorophyll and nitrogen concentrations, utilising partial least square regression model, was lower for the infested compared to the healthy trees. We show that early stage of infestation reduces not only foliar biochemical content but also their retrieval accuracy. Our results further indicate that remote sensing measurements can be successfully used for the early detection of the bark beetle infestation. We demonstrated that bark beetle infestation at the green attack stage effects leaf spectral response as well as leaf biochemical properties and their retrievals from hyperspectral measurements.
\end{abstract}

\section{Introduction}

Bark beetles (Ips typographus, L., and Dendroctonus spp.) are important biotic disturbance agents in the coniferous forests of Europe and North America, respectively (Christiansen and Bakke, 1988; Fahse and Heurich, 2011; Raffa et al., 2008; Seidl et al., 2011; Seidl et al., 2014). In the past decades, an increasing number of severe bark beetle outbreaks has led to an extensive economic loss in the forest industry (Goheen and Hansen, 1993; Waring et al., 2009). The economic impacts include a reduction in the commercial value of the infested trees and increased management costs (Schowalter, 2012). Besides causing economic losses, outbreaks of the bark beetle form an important factor in the ecological development of the forest landscape, in terms of forest structure and composition (Pfeifer et al., 2011; Schowalter, 2012; Simard et al., 2012; Zeppenfeld et al., 2015), as well as biodiversity and ecosystem services (Thom and Seidl, 2015). Bark beetles can affect forest ecosystems both directly and indirectly. Direct impacts include an increase in tree mortality rates and a reduction in forest stand densities (Bright et al., 2013; Eitel et al., 2011; Filchev, 2012; Hais and Kučera, 2008; Schowalter, 2012; Vanderhoof et al., 2013; Verbesselt et al.,

\footnotetext{
* Corresponding author.

E-mail address: h.j.abdullah@utwente.nl (H. Abdullah).
} 
2009). Other indirect impacts are; reduction in carbon uptake, changes in tree species' distribution, as well as changes in erosion processes, fire frequency, and nutrient cycling (Beudert et al., 2015; Kurz et al., 2008; Lehnert et al., 2013; Lindenmayer and Franklin, 2002; Mikkelson et al., 2013). Additionally, recent studies showed that the infestation of bark beetle leads to biodiversity enhancement by opening the canopy layers and altering microclimate condition in the forest. This alteration will provide the essential habitats and sources of energy for various organisms, and allow them to persist in the disturbed areas by bark beetle (Beudert et al., 2015; Lehnert et al., 2013; Müller et al., 2008).

The phenology of bark beetle and the associated host responses are well described in Wermelinger, (2004). The infested tree goes through three stages of attack (Coulson et al., 1985; Sprintsin et al., 2011; Wermelinger, 2004). These stages are termed green, red and grey attacks, respectively. During the green attack stage, the foliage remains green (hence the name green attack), and therefore, it is difficult to detect this stage by the human eye at leaf and canopy levels (Niemann and Visintini, 2005; Wulder et al., 2006). However, the subsequent degradation of the needles can be noted by regular field observations, as, during the red attack stage, the needles of the tree turn from green to yellow and red-brown. Finally, the needles fall off, and only the grey bark will remain, hence the last stage being called a grey attack. This discolouration of the attacked trees is evident at canopy level (Coulson et al., 1985). It is expected that bark beetle infestation induces changes in the spectral response of the infested trees (Filchev, 2012; Meddens et al., 2013), as the biophysical characteristics of the entire tree, and very likely the biochemical features of the needles, change. Therefore, during the infestation period, the trees are subjected to increasing stress and face physiological change (Heath, 2001). This is due to the interruption of the water flow and the deterioration of chloroplasts as the beetle drills into the tree's cambium tissue (Yamaoka et al., 1990). The fungi carried by the beetles penetrate the living phloem and xylem cells, hampering the translocation of water, sugar and other nutrients within the bole of the tree (Paine et al., 1997; Rohde et al., 1996; Safranyik et al., 2007; Wermelinger, 2004). This leads to a gradual change in biochemical and water content in the attacked tree, thus inducing alterations to its spectral characteristics over the course of the infestation (Deshayes et al., 2006; Lawrence and Labus, 2003; Marx and an der Havel, 2010; Reid, 1961; Sprintsin et al., 2011; Yamaoka et al., 1990)

A considerable increase in unplanned harvesting of European forests following bark beetle infestation has led to increased research interest in understanding the dynamics and improving the management of Ips typographus, L. outbreaks (Seidl et al., 2011). Furthermore, an increase in the frequency and severity of bark beetle outbreaks is expected due to global climate change (Bentz et al., 2010). Consequently, more attention is devoted to this topic. It has also been evoked to increase discussion regarding salvage logging in protected areas in Europe (Lehnert et al., 2013). Early detection of Ips typographus, L. outbreaks at the green attack stage may prove an important step, as management aims to control this species and preclude a mass outbreak. At the green attack stage, the trees hold the next generation of beetles. Management intervention to prevent further outbreaks may, therefore, involve the removal of infested trees before the new brood emerges and migrates (Wermelinger, 2004; Wulder et al., 2009). Traditionally, foresters have performed field surveys to identify infested trees; such surveys are very laborious, costly, and therefore it is inefficient and hard to apply for management purposes in large areas. Remote sensing has the potential to detect pest infestations over large areas in relatively short periods of time. Employing remotely sensed data allows monitoring of the changes in leaf and canopy properties before and after insect infestation (Bentz and Endreson, 2003; Deshayes et al., 2006; Dye et al., 2008; Jensen, 2009). To date, the utilisation of remote sensing for the monitoring and detection of bark beetles by forest managers has mainly focused on the last two attack stages (i.e., the red and grey stage) and has achieved high degrees of accuracy. During the last two stages of the attack, the changes in canopy colour effect the spectral reflectance signature which are mainly been used as an indicator to detect infestations (Carter et al., 1998; Franklin et al., 2003; Heurich et al., 2010b; Latifi et al., 2014; Meddens, 2012; Nikolov et al., 2014; Skakun et al., 2003; Wulder et al., 2006). However, detecting the infestation in the last two stages is not sufficient for appropriate management, as phenological research proved that during the red attack stage the newly developed beetles have already left their host trees and started to attack new trees. Therefore, the continuing of an outbreak can not be prevented by salvage logging during this stage. Consequently, the detection of the bark beetle at the green attack stage by means of remote sensing is necessary to have a meaningful effect on the spreading of the beetle, but is challenging due to the lack of apparent visual symptoms in needles.

Early detection of infestations by Dendroctonus spp in lodgepole pine trees has been investigated at canopy level (Gimbarzevsky et al., 1992; Heath, 2001; Klein, 1973; Murtha and Wiart, 1989; Murtha, 1972). Similarly, detection of a bark beetle green attack (Ips typographus, L.) at canopy level in Norway spruce trees has been investigated by (Immitzer and Atzberger, 2014; Lausch et al., 2013; Marx and an der Havel, 2010; Ortiz et al., 2013). However, these studies did not succeed in discriminating healthy from green attacked trees. More recently, Niemann et al. (2015) used LIDAR and hyperspectral data to examine the spectral properties of healthy trees and those under mountain pine beetle green attack and demonstrated that the most promising wavelengths, for the detection of mountain pine beetle at green attack stage, is located in the shortwave infrared region. Furthermore, Näsi et al. (2015) used a hyperspectral sensor (500-900 nm) mounted on an unmanned aerial vehicle (UAV) to map bark beetle damage at the tree level, by dividing tree stands into three different classes (healthy including trees with potential early infestation stage, red attack; and dead). They found that the healthy and dead trees can be classified with $90 \%$ over-all accuracy, however, when all classes were considered (healthy, red and dead), the overall accuracy dropped to $76 \%$.

At the leaf level, there are very few studies, although with different beetle and tree species, that have examined the differences in spectral reflectance between healthy needles and those that have been under bark beetle green attack (Ahern, 1988; Cheng et al., 2010; Foster et al., 2017). In addition to a change in spectral reflectance properties, Cheng et al. (2010) observed that there were differences in water content of healthy and infested needles, particularly, between 1318 and $1322 \mathrm{~nm}$.

These results show that remote sensing has the potential to detect early stages of bark beetle attacks. However, these studies have mostly considered the effect of early infestation on reflectance spectra and not on the biochemical properties of the needles. Therefore, it is highly important to understand whether, in addition to the spectral reflectance, the biochemical properties are also affected at the bark beetle early infestation stage. Consequently, the topic warrants further investigation.

As mentioned earlier, it is expected that the infested tree will exhibit a change in terms of its biochemical and spectral properties, due to the beetle larva and blue stain fungi such as (Ophiostoma and Cerato-cystis species) carried by the beetles starts to penetrate the living phloem and xylem cells, hampering the translocation of water, sugar and other nutrients within the bole of the tree (Paine et al., 1997; Rohde et al., 1996; Safranyik et al., 2007; Wermelinger, 2004).Therefore, in this study, we aim to investigate the possible early detection of a bark beetle green attack by examining and comparing the foliar biochemical (chlorophyll and nitrogen) and spectral properties (400-2000 nm) of both healthy and green attacked trees. Chlorophyll and nitrogen are two important elements that have a key role to play in plant life and status and can be considered as indicators that reflect the status of plant growth and health (Heinze and Fiedler, 1976; van Maarschalkerweerd and Husted, 2015; Wang et al., 2015a; Wang et al., 2015b). As such changes, initiated by bark beetle attack cause stress during the infestation time, we hypothesise that chlorophyll and nitrogen concentrations are reduced during such an attack. These can thus provide suitable proxies for detecting the presence of Ips typographus L. during a 


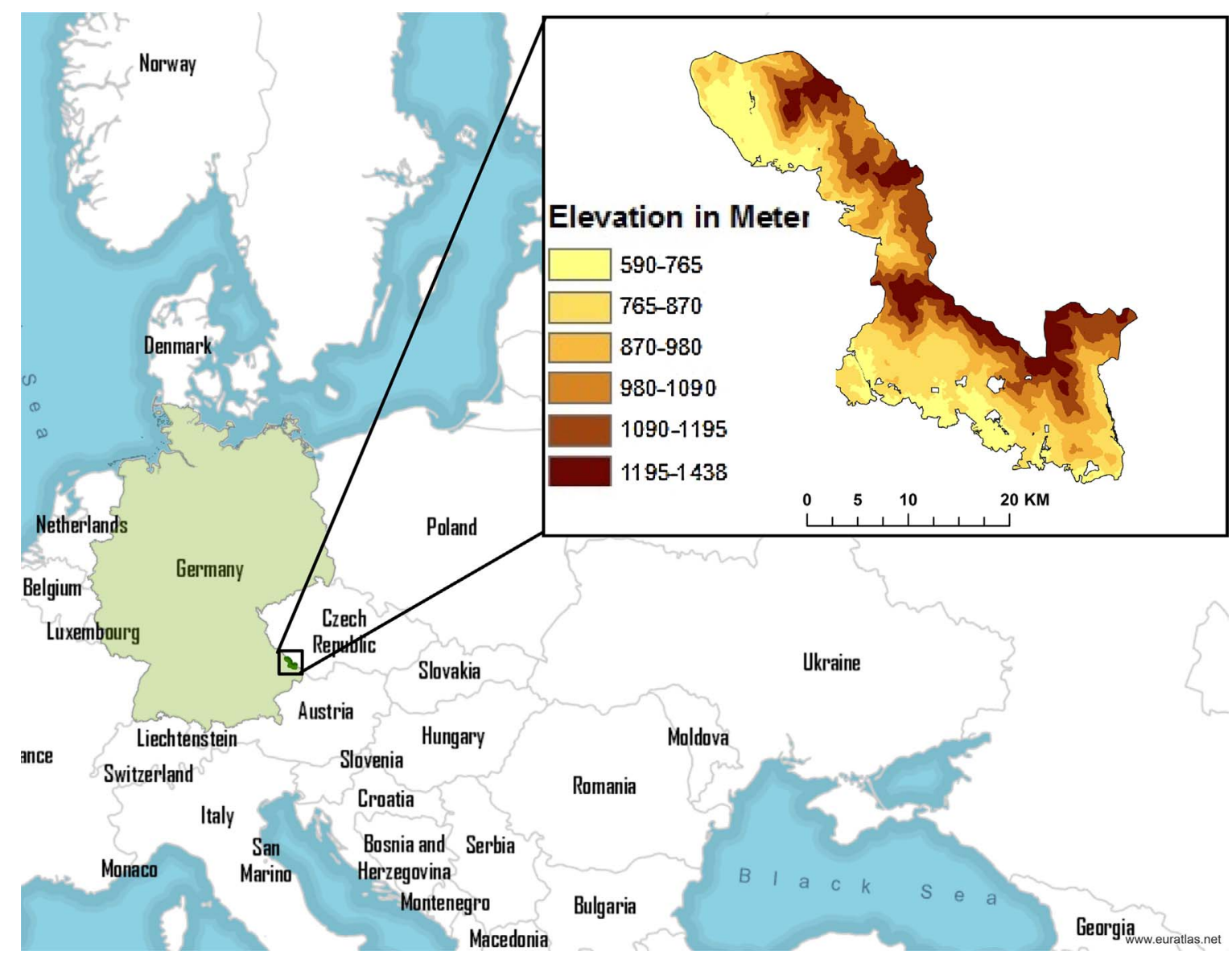

Fig. 1. The location of Bavarian Forest National park in Central Europe.

green attack stage. Specifically, there are three main objectives: (a) to investigate the impact of an Ips typographus L. green attack on folair spectral reflectance; (b) to examine the changes in folair biochemical properties due to the Ips typographus L. green attack; (c) to explore the impact of the Ips typographus L. green attack on the estimation accuracy of folair biochemical properties utilizing hyperspectral measurements.

\section{Material and methods}

\subsection{Study area}

The study area is the Bavarian Forest National Park (BFNP) in southeast Germany, which covers an area of $240 \mathrm{~km}^{2}$ between $13^{\circ} 12^{\prime} 9^{\prime \prime} \mathrm{E}$ (longitude) and $49^{\circ} 3^{\prime} 19^{\prime \prime} \mathrm{N}$ (latitude) (Fig.1). The elevation in the BFNP ranges from $600 \mathrm{~m}$ to $1453 \mathrm{~m}$. This region is characterised as having a temperate climate with a total annual precipitation along the gradient between 900 and $1800 \mathrm{~mm}$ as well as a mean annual temperature that varies between 3.5 and $7.2^{\circ} \mathrm{C}$ (Bässler et al., 2008; Lehnert et al., 2013). The area is divided into three ecological zones: high elevations, hillsides, and valley bottoms. Around $90 \%$ of the tree stands in high elevations are Norway spruce (Picea abies (L.) Karst), $2 \%$ are beech (Fagus sylvatica L.), and the remaining $8 \%$ are covered by other broad-leaves trees, mainly Common Rowan (Sorbus aucuparia). While on the hillsides, around $58 \%$ is occupied by Norway spruce, and the rest is a mixture of European silver fir (Abies alba) and beech. In the valley bottoms, $83 \%$ of the trees are Norway spruce, and the rest is a mix of species (Cailleret et al., 2014; Heurich et al., 2010a). Multiple storm events in the 1980s and a series of hot summers in the 1990s have lead to an extensive mortality of canopy trees by bark beetles on about 8000 ha (Lausch et al., 2013).

\subsection{Data acquisition}

The adult bark beetle starts to attack new host trees during the European springtime (between the end of April and the beginning of May). This process strongly depends on the air temperature as the beetles start their swarming when the air temperature reaches $16.5^{\circ} \mathrm{C}$ (Lobinger, 1994; Wermelinger, 2004). Therefore, the field data were collected in the early summer of 2015 within 15-30 days from the early stages of infestation. In total 120 trees were measured, of which 66 were healthy, and 54 were freshly infested trees. An extensive field survey was conducted to identify the trees under bark beetle green attack by spotting piles of dry, boring dust, which had been pushed out onto the bark surface (Fig. 2). An Average of 2-3 branches were taken from each tree. Needle samples from each branch were collected separately. All the branches were taken from the upper part of the trees, which was exposed to the sunlight.The heights of the trees varied between approximately 25 and $30 \mathrm{~m}$. A crossbow was used to shoot an arrow with a fishing line attached to a branch with sunlit leaves (Ali et al., 2016). The fishing line was used to feed a rope over the targeted branch. Once the rope was in place, the branch was pulled down gently until it broke off. Needles were immediately removed from the fallen branches and placed in a labelled plastic zip-locked bag, which was then covered with wet pulp paper and subsequently transported to the laboratory in a portable cooling box filled with frozen ice packs to keep the sample cool. The aim was to retard, as much as possible, any changes in the needles' reflectance spectra and biochemical characteristics (Malenovský et al., 2006). Once the spectral measurements were completed, the same sample branch was transported to the laboratory to measure the fresh weight, leaf area and the biochemical properties of the foliar samples. 


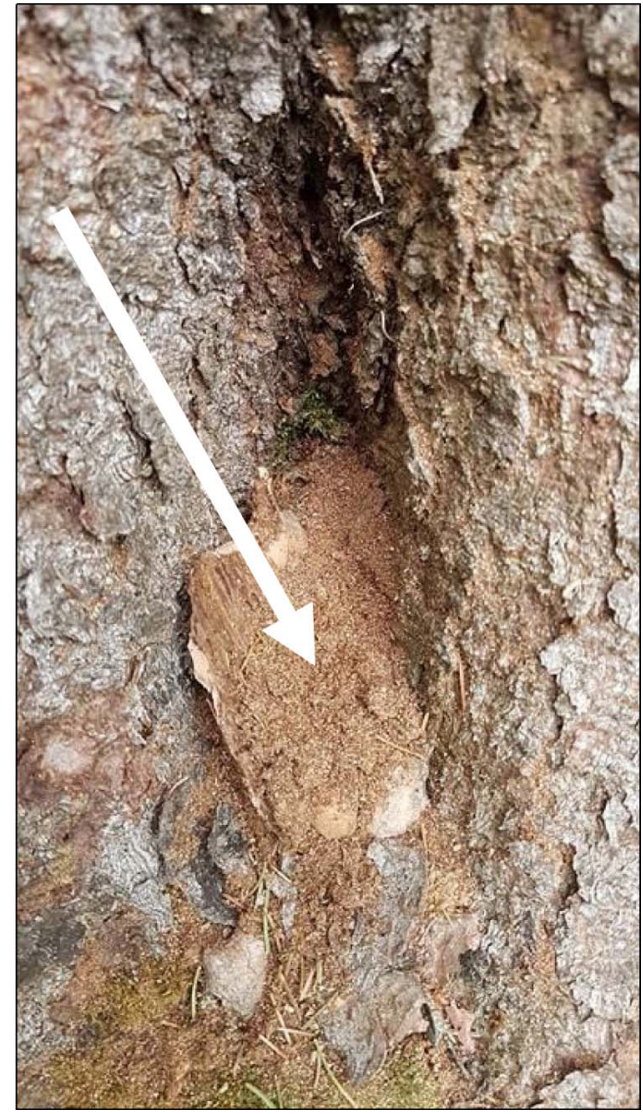

Fig. 2. Dry dust produced through boring by the bark beetle Ips typographus, L.; used to identify freshly infested trees in the field.

\subsection{Chemical analyses}

The concentration of Chlorophyll $a$ and $b$ in the collected fresh leaf samples was determined destructively by a spectrophotometer following the Lichtenthaler (1987) method using acetone (v 100\%). In addition, to determine foliar nitrogen, the needles were dried for $72 \mathrm{~h}$ using an oven dryer at $60^{\circ} \mathrm{C}$. The dried needles were properly grounded using mortar and pestle until the ground leaves became a soft powder and were passed through a $0.25 \mathrm{~mm}$ mesh screen. Subsequently, $2 \mathrm{mg}$ of powdered leaves was transferred to a small aluminium capsule to measure the nitrogen content, using an organic elemental analyser (FLASH 2000).

\subsection{Reflectance measurements}

The leaf directional hemispherical reflectance from 350 to $2500 \mathrm{~nm}$ was measured for collected samples, using an ASD FieldSepc-3 Pro FR spectrometer equipped with an ASD RT3-3ZC integrating sphere (Analytical Spectral Devices, Inc., Boulder, Co, USA). The integrating sphere had a port diameter of $15 \mathrm{~mm}$ for a reflectance measurement. The Norway spruce needles did, however, not cover the entire sample port of the integrating sphere. Therefore, the method proposed by Daughtry et al. (1989) was applied, where a universal sample holder, designed by Malenovský et al. (2006), was used to accommodate all sizes and lengths of Norway spruce needles. For every measurement five to six needles were secured on the sample holder with cellophane tape, leaving a gap of one needle's width between needles to avoid multiple reflectances of the adjusted needles (Ali et al., 2016; Daughtry et al., 1989). To minimise the effect of spectral signal noise, for every needle sample two hundred scans were averaged to present a single spectrum. The integrating sphere has an internal light source, and therefore, the sun angle and cloudiness does not affect the spectral measurement (Foster et al., 2017). However, to prevent possible light entering into the integrating sphere ports, covering the integrating sphere with a black piece of cloth is recommended by Mesarch et al. (1999).

The measured spectral reflectance from the sample holder contained the effects of the gap between the attached needles to the sample holder; therefore, the spectral measurements were corrected by calculation of the gap fraction. To do so, a black painted paper mask with a 15 -mm diameter circular aperture was precisely superimposed onto the samples and photographs were taken using a 16.1 megapixel Panasonic LUMIX camera (Ali et al., 2016). Then, the images were imported into ImageJ software (Schneider et al., 2012), to compute the gap fraction, based on the illuminated area of the sample port. The following equation was adapted from Mesarch et al. (1999) for the Field ASD spectrometer and to compute the hemispherical reflectance of the sample needles:

Reflectance $=[(\rho-\mathrm{Rd} / 1-\mathrm{Rd}) \times \mathrm{Rr}] /(1-\mathrm{GF}) ;$

where: $\rho$ is the measured reflectance from the sample holder; Rd is stray light (ambient light) inside the integrating sphere, measured as a radiation flux of the empty illuminated sample port in reflectance mode; $\mathrm{Rr}$, is reference of sample reflectance; and GF is the gap fraction of the sample.

\subsection{Data preprocessing and statistical analysis}

A series of pre-processing steps were performed on the measured reflectance data. First, the spectral reflectance was examined, and "noisy" bands (in the spectral ranges 350-399 nm and 2000-2500 nm) were excluded from the analysis. Secondly, to eliminate and reduce the sensor noise, a Savitzky - Golay smoothing filter with a frame size of 15 (2nd-degree polynomial) was applied to the reflectance spectra (Savitzky and Golay, 1964).

The significance of differences $(\mathrm{p} \leq 0.05)$ in foliar reflectance as well as chlorophyll and nitrogen concentration between leaf samples from green attacked and healthy trees, was examined using Student $t$ tests, in order to determine whether there is spectral variation at any spectral band. Because the considered adjacent wavelengths are highly correlated, we corrected the p-value using Holm (1979) procedure, next the significant wavebands with mean reflectance spectra of both healthy and infested samples were plotted following the technique used by Schmidt and Skidmore (2003).

To investigate the relationship between the spectral reflectance of the healthy and infested samples and their biochemical parameters, the Pearson's correlation coefficients were calculated between spectral reflectance $(400-2000 \mathrm{~nm})$ and chlorophyll as well as nitrogen concentration for both healthy and infested samples to identify the most sensitive wavebands in healthy and infested samples.

\subsubsection{Partial least square regression model (PLSR)}

Partial least squares regression (PLSR) was used to investigate the impact of the bark beetle green attack stage on the retrieval accuracy of the chlorophyll and nitrogen concentrations in needles. PLSR is a regression method that takes into account both the variance of the explanatory and the dependent variables. It specifies a linear relationship between a set of dependent $(\mathrm{Y})$ variables and a set of predictor $(\mathrm{X})$ variables (Wold et al., 2001). PLSR performs particularly well when the various $\mathrm{X}$-variables have strong correlations, as is normally the case with hyperspectral data. (Carrascal et al., 2009; Nicolaï et al., 2007). Further details on PLSR can be found in Geladi and Kowalski (1986).

PLSR was used to predict the foliar chlorophyll and nitrogen concentrations (dependent variables) of the healthy and infested needles from spectral reflectance (predictor variables). PLSR models were built independently for the healthy and infested samples. For the chlorophyll 
concentration, PLSR was fitted to the VNIR range (400-790 nm), as this spectral region mainly contributes to total chlorophyll estimation in plants (Curran, 1989; Yoder and Pettigrew-Crosby, 1995). However, as nitrogen is associated with many other leaf chemical compounds, the spectral wavebands corresponding to nitrogen are distributed over the whole spectrum (VIR, NIR, SWIR) (Curran, 1989; Peterson et al., 1988) and consequently, for the nitrogen concentration, PLSR was fitted to the entire spectrum (400-2000 nm). To determine the number of components needed to build the PLSR model, Monte Carlo cross-validation (MCCV) was applied (Xu and Liang, 2001). The procedure involves adding an extra component to the model when the value of the root mean square error of cross-validation (RMSEcv) is reduced by $\geq 2 \%$ (Darvishzadeh et al., 2008; Geladi and Kowalski, 1986). The performance of the PLSR models were assessed by computing the coefficient of determinations $\left(\mathrm{R}^{2}\right)$, the normalised root mean square error of predictions (nRMSE $E_{\mathrm{P}}$ ) and normalised root mean square error of crossvalidations (nRMSE $\mathrm{CV}_{\mathrm{CV}}$ ) of predicted versus measured values.

We further examined whether the most informative wavelengths for the estimation of chlorophyll and nitrogen concentrations in both healthy and infested samples correspond. To achieve this, the variable importance in the projection (VIP) was calculated for all wavebands from the PLSR models. VIP scores summarise the influence of individual $\mathrm{X}$ variables (reflectance) in the PLSR model. A variable with a VIP score close to, or greater than 1 , can be considered significant in a given model (Chong and Jun 2005; Tenenhaus, 1998; Wold et al., 1993). A detailed description of the calculation of VIP scores can be found in Farrés et al. (2015); Wold et al. (1993). TOMCAT and libPLS toolbox was used within MATLAB to establish PLSR analysis and calculate VIP score, respectively (Daszykowski et al., 2007; Li et al., 2014).

\section{Results}

\subsection{Spectral reflectance variation due to bark beetle green attack}

The results demonstrated that the mean reflectance spectra of healthy and green attacked foliage were statistically different ( $p \leq 0.05$ ) for 917 wavebands out of the 1600 wavebands used in this study (Fig. 3). As can be seen from Fig. 3, a clear distinction was observed in the mean reflectance between healthy and infested foliage in the visible and near-infrared regions. In the visible region, the mean reflectance of the infested foliage was higher than of the healthy leaves, in conjunction with chlorophyll degradation (Fig. 4). However, there was a larger difference ( $\mathrm{p} \leq 0.05)$ between infested and healthy needles in the wavelength range $730-1370 \mathrm{~nm}$, as the healthy needles had higher reflectance compared to mean infested spectra.

\subsection{Impact of bark beetle green attacks on foliar biochemical properties}

A Student $t$-test demonstrated a significant difference between total chlorophyll and foliar nitrogen concentrations of healthy and infested leaves $(\mathrm{p}<0.05)$. In healthy foliage, the mean and \pm of the total chlorophyll concentration were $0.766 \pm 0.140 \mathrm{mg} / \mathrm{g}$, respectively, whereas for the green attacked leaves they were $0.657 \pm 1.62 \mathrm{mg} / \mathrm{g}$, respectively. Furthermore, the concentration of nitrogen was $1.25 \pm 0.21 \%$ within healthy leaves, while for the infested leaves they were $1.13 \pm 0.18 \%$, respectively (Fig. 4). The correlation between total chlorophyll and nitrogen concentration was higher in needles from healthy trees $(r=0.68, p<0.05)$ than in needles from green attacked trees $(\mathrm{r}=0.57, \mathrm{p}<0.05)$.

\subsection{Effects of bark beetle green attack on the retrieval accuracy of leaf biochemical properties}

The impact of bark beetle green attack on the retrieval accuracy of foliar chlorophyll and nitrogen concentrations was assessed using PLSR. In general, higher accuracies were observed when healthy samples were assessed (Table 1). For healthy foliage, the coefficients of determination for chlorophyll and nitrogen concentrations were $\mathrm{R}^{2}=0.64$ and $\mathrm{R}^{2}=0.76$, respectively. However, these coefficients decreased for models fitted to data from infested foliage, both for chlorophyll $\left(R^{2}=0.55\right)$ and for nitrogen $\left(R^{2}=0.68\right)$ (Table 1$)$. Similar results were discerned with the Pearson correlation coefficient between chlorophyll and the reflectance data, as well as between nitrogen and the reflectance data. As can be observed from Fig. 6, significantly higher correlations were observed for healthy leaves than for infested leaves. In addition, the prediction error for chlorophyll in healthy leaves (nRSMSEp $=0.20$ ) was much lower than for chlorophyll in infested leaves (nRMSEp $=0.62$ ) (Fig. 5). However, this variation in nRMSEp for nitrogen content was much lower $(0.12$ and 0.22$)$ in both healthy and infested samples respectively.

As shown in Figs. 6 and 7, the spectral regions, in particular, the green and the red edge (536-559 $\mathrm{nm}$ and $732-790 \mathrm{~nm}$, respectively), demonstrated the highest VIP (VIP $>1$ ) and a moderately negative correlation $(r=-0.41$ and -0.32 , for the green and red edge, respectively; $\mathrm{P}<0.05$ ) between chlorophyll and the reflectance spectra of healthy foliage. The high VIP value indicated that the spectral feature was of major importance in estimating the chlorophyll concentration. A weaker negative correlation with a lower VIP score was observed for the infested samples $(r=-0.12, P<0.05)$.

The spectral regions that were most sensitive to changes in nitrogen content were in the range of $980-1000 \mathrm{~nm}$ and $1448-1469 \mathrm{~nm}$, where

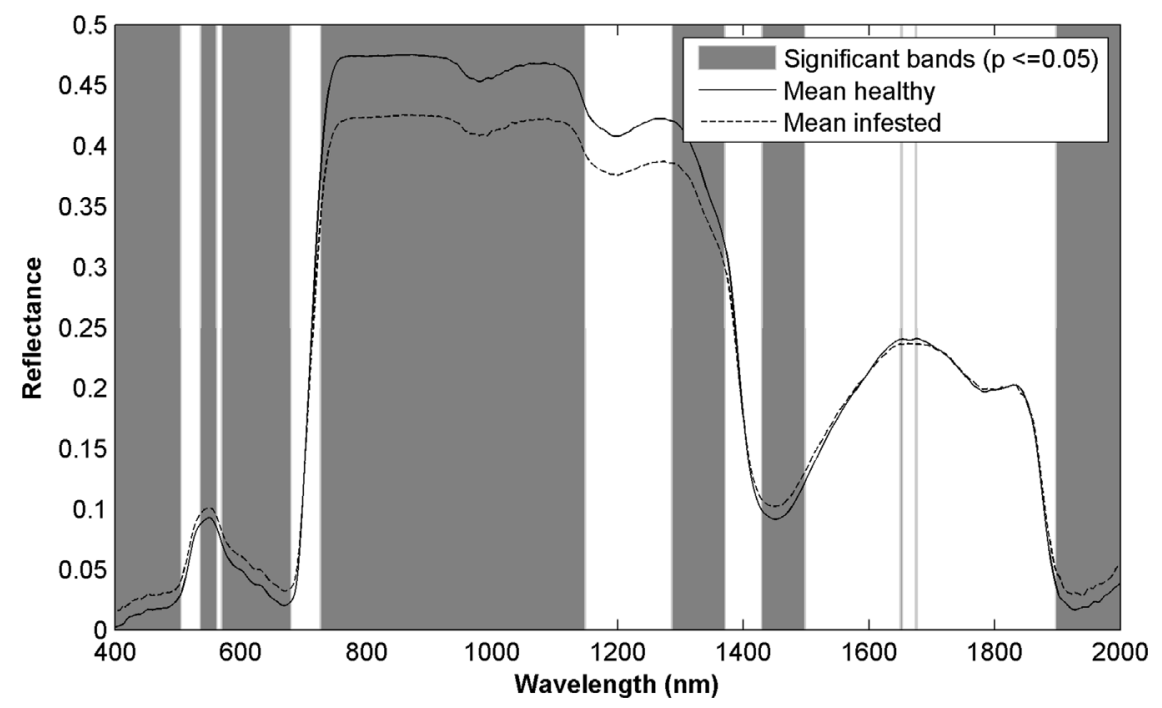

Fig. 3. Mean reflectance spectra of healthy and infested leaves at the green attack stage. Gray areas depict the location of wavebands displaying is a significant difference between healthy and infested spectra. 

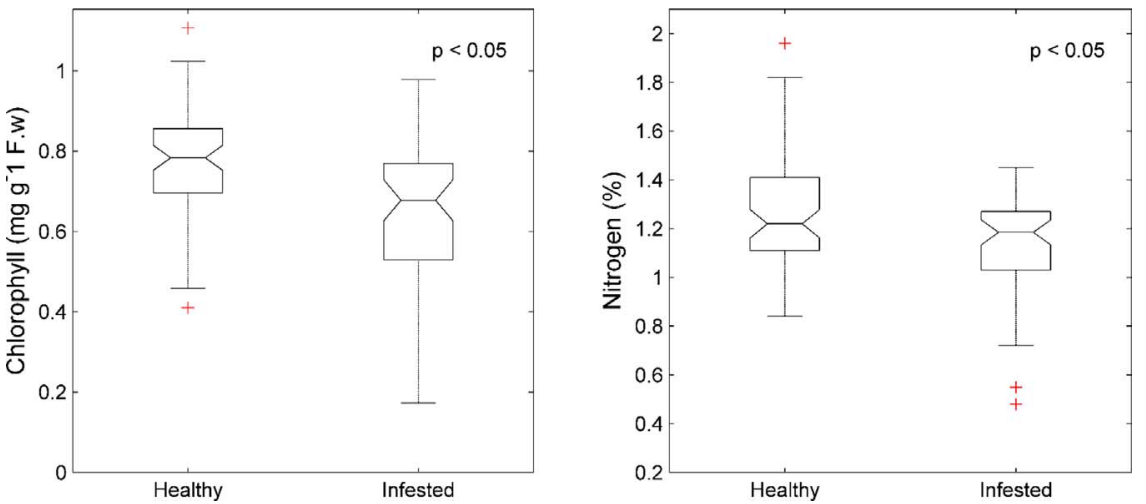

Fig. 4. Distribution of measured chlorophyll and nitrogen concentration for healthy and infested needles. There is a significant difference $(\mathrm{p}<0.05)$ in chlorophyll and foliar nitrogen concentration between healthy and infested sample.
Table 1

Number of latent variables, $\mathrm{R}^{2}$ and nRMSEp between measured and predicted chlorophyll and nitrogen in healthy and green attacked needles.

\begin{tabular}{llllll}
\hline $\begin{array}{l}\text { Sample } \\
\text { Condition }\end{array}$ & Variables & $\begin{array}{l}\text { Nr. Of latent } \\
\text { variables }\end{array}$ & nRMSE $_{\mathrm{P}}$ & $\mathrm{nRMSE}_{\mathrm{CV}}$ & $\mathrm{R}^{2}$ \\
\hline Healthy & $\mathrm{Chl}$ & 9 & 0.20 & 0.24 & 0.64 \\
& $\mathrm{~N}$ & 10 & 0.12 & 0.20 & 0.76 \\
Infested & $\mathrm{Chl}$ & 10 & 0.62 & 0.75 & 0.55 \\
& $\mathrm{~N}$ & 8 & 0.22 & 0.35 & 0.68 \\
\hline
\end{tabular}

the infested leaves had a lower VIP score (Fig. 6). Furthermore, the correlation coefficients between foliar nitrogen concentration and the reflectance spectra show a distinct variation between healthy and infested foliage, especially in the spectral region between 720-1400 nm.
The healthy foliage showed a moderately negative correlation $(\mathrm{r}=-0.30, \mathrm{P}<0.05)$, while for the infested foliage a positive correlation was found (Fig. 6).

\section{Discussion}

It has long been believed that the detection of bark beetle green attack using remote sensing data is a challenging task (Wulder et al., 2009; Niemann and Visintini, 2005). However, recent studies have shown that remote sensing data obtained across a number of wavelengths have the potential for the detection of bark beetle green attack (Cheng et al., 2010; Foster et al., 2017; Niemann et al., 2015). In this study, we investigated whether bark beetle green attack has a concurrent effect on key foliar biochemical properties (i.e. chlorophyll and nitrogen concentration) as well as spectral responses $(400-2000 \mathrm{~nm})$.
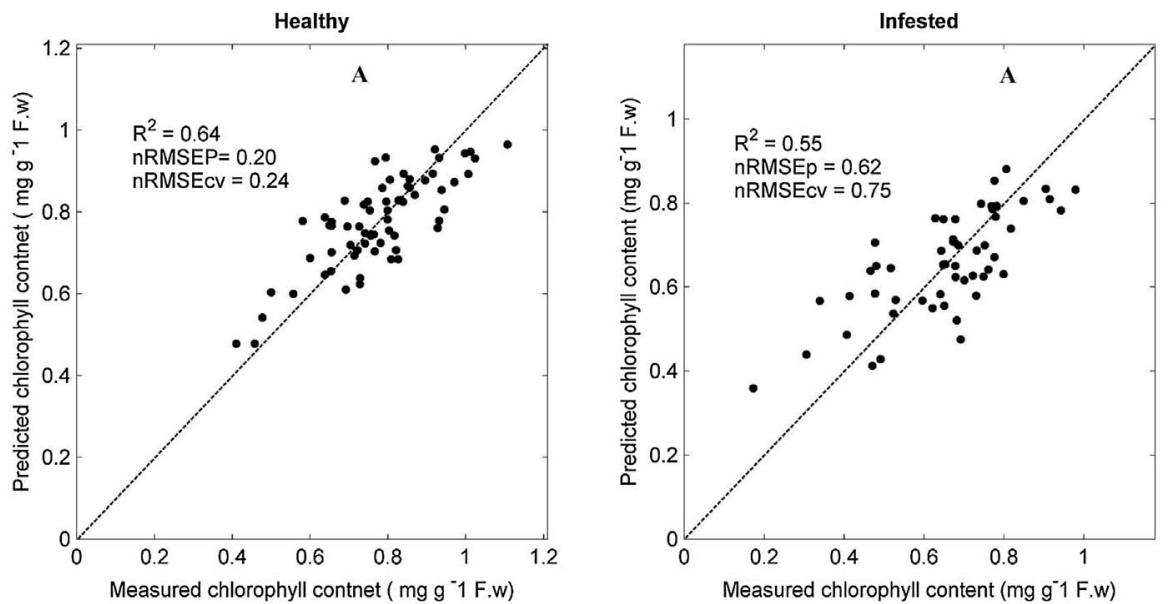

Fig. 5. Measured versus predicted foliar chlorophyll (a) and nitrogen (b) concentration for healthy and infested samples derived from the PLSR analysis.
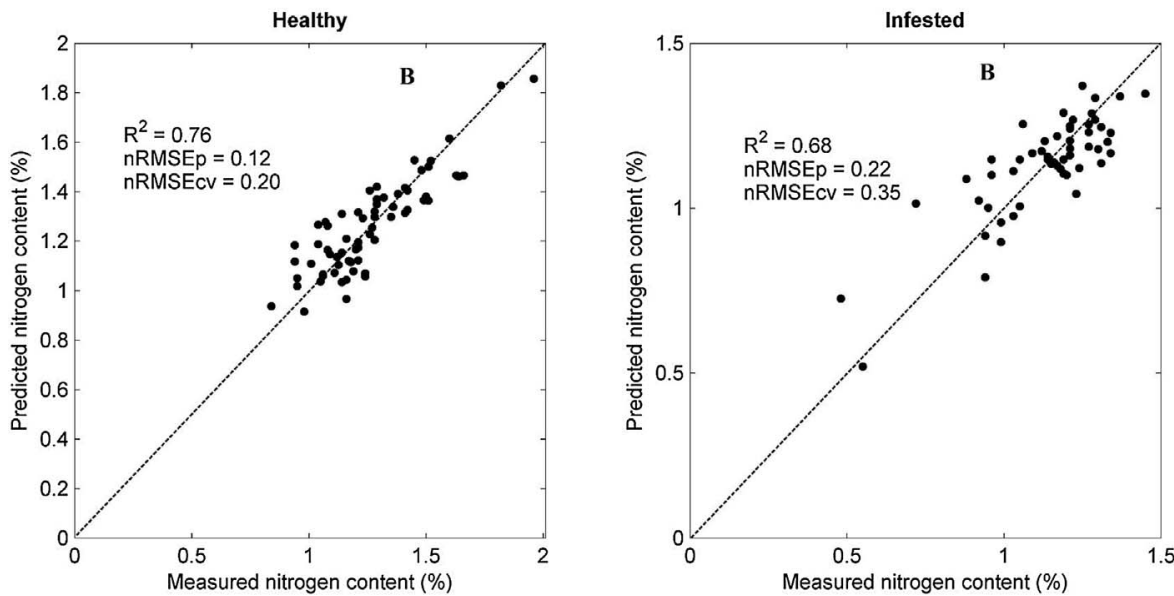

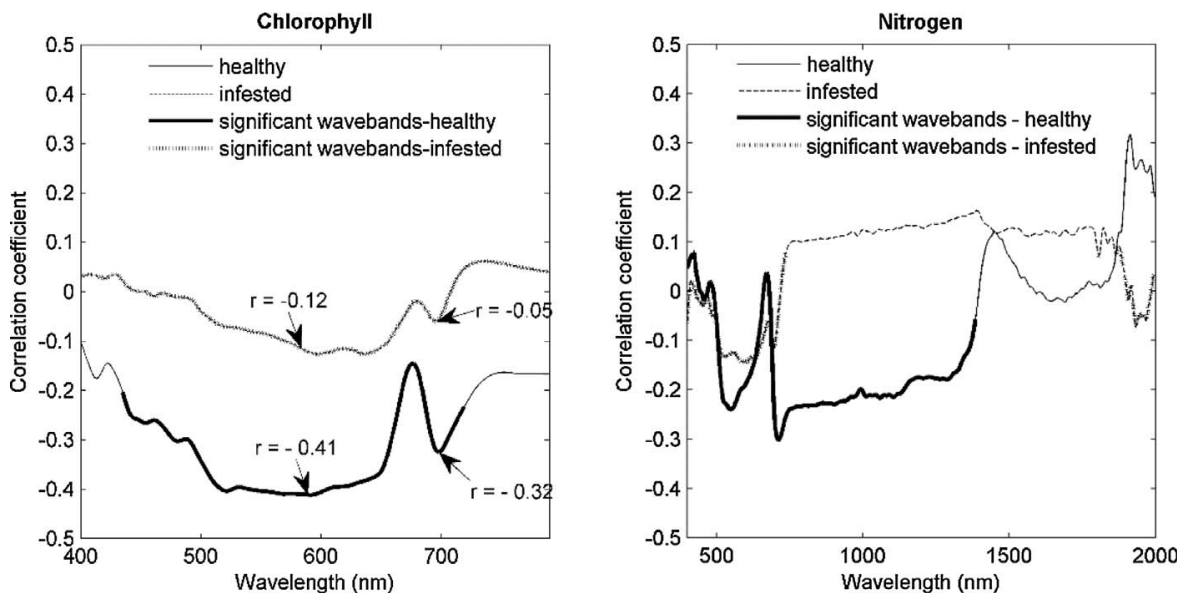

Fig. 6. Correlation between chlorophyll and nitrogen and the reflectance of individual wavebands. The bold lines represent the wavebands at which the reflectance spectra correlated significantly with the chlorophyll and nitrogen concentrations. The arrows show the wavebands in which recorded the highest correlation with chlorophyll content in both healthy and infested samples.

The results demonstrate that the foliar reflectance of needles from green attacked trees differs significantly from healthy needles ( $\mathrm{p} \leq 0.05)$, in particular between wavelengths of 730 and $1370 \mathrm{~nm}$. Furthermore, the infestation significantly $(\mathrm{p} \leq 0.05)$ affected the biochemical concentrations of total chlorophyll and foliar nitrogen and reduced their retrieval accuracy using PLSR (Figs. 3 and 4).

The measured reflectance spectra of healthy needles matched those of similar studies which measured needle reflectance of Norway Spruce (Ali et al., 2016; Atzberger and Werner, 1998; Kováč et al., 2012). However, there were significant differences observed between the reflectance spectra of the healthy and the green attacked samples. This can be attributed to differences in their foliar biochemical properties, especially to their chlorophyll concentration which is known to be effected by vegetation stress. In our study, the reflectance increased in the visible region, and decreased in the NIR, for the green attack leaves. This is in line with the findings of Ahern (1988), who studied the spectral range of $400-1100 \mathrm{~nm}$ and showed that the spectral band at the green peak increased for the lodgepole pine needles infested by similar beetle species (Mountain pine beetle) at the green attack stage. In the visible region, the concentration of pigments such as total chlorophyll is the main factor for determining leaf spectral variation and absorption peaks (Carter and Knapp, 2001; Demetriades-Shah et al., 1990; Feret et al., 2008; Zhang et al., 2008). The infested trees had significantly $(\mathrm{p}<0.05)$ lower chlorophyll and foliar nitrogen concentrations than the healthy ones, resulting in lower absorption and higher scattering (Figs. 3 and 4). The observed behaviour of the reflectance spectra in the visible region in this study is a clear indication of stress caused by early infestation and is in agreement with the results of earlier studies focused on plant stress (Carter, 1993; Carter and Knapp, 2001; Zarco-Tejada and Sepulcre-Cantó, 2007). Furthermore, wavelength ranges between 730 and $790 \mathrm{~nm}$ that contained the most informative spectral region regarding variations in chlorophyll concentration, demonstrated the greatest amount of dissimilarity (58 wavebands) between the healthy and infested leaf samples (Fig. 7). This spectral region is often referred as red-edge, and it responds quickly to changes in foliar chlorophyll (Carter, 1993; Carter and Knapp, 2001; Smith et al., 2004). This is in good agreement with finding by Lottering et al. (2016), as they studied the utility of spectral vegetation indices derived from WorldView-2 data in detecting and mapping $G$. scutellatus induced vegetation defoliation. Their result showed that the combination between red-edge and NIR region has the potential to detect stress induced by $G$. scutellatus insect.

Moreover, as noted in Fig. 3, the more pronounced changes in the reflectance spectra were observed at the wavelength region between the NIR and SWIR regions (730-1370 nm), where the reflectance of the infested leaves was distinctively lower than that of the healthy ones. This can probably be explained by the changes in water content that occur due to the infestation, which leads to a degeneration of the internal leaf structure at the cellular level (Miller et al., 1991; Murtha, 1978; Paine et al., 1997; Slaton et al., 2001; Zhang et al., 2012). This result partially agrees with the findings of Niemann et al. (2015), who demonstrated that at the wavelength of $970 \mathrm{~nm}$ there was no separation between healthy trees and samples infested by mountain pine beetle, while at the wavelength of $1200 \mathrm{~nm}$ a significant difference existed between them. Additionally, Ismail and Mutanga (2010) showed the importance of the wavelength between 900 and $1110 \mathrm{~nm}$ and identified both Ratio $_{975}$ and water index has the ability to assess water stress induced by $S$. noctilio in $P$. patula trees from an early stage of infestation when there is no sign of infestation at the canopy level.

In addition to the variations in VIS and NIR, the reflectance spectra
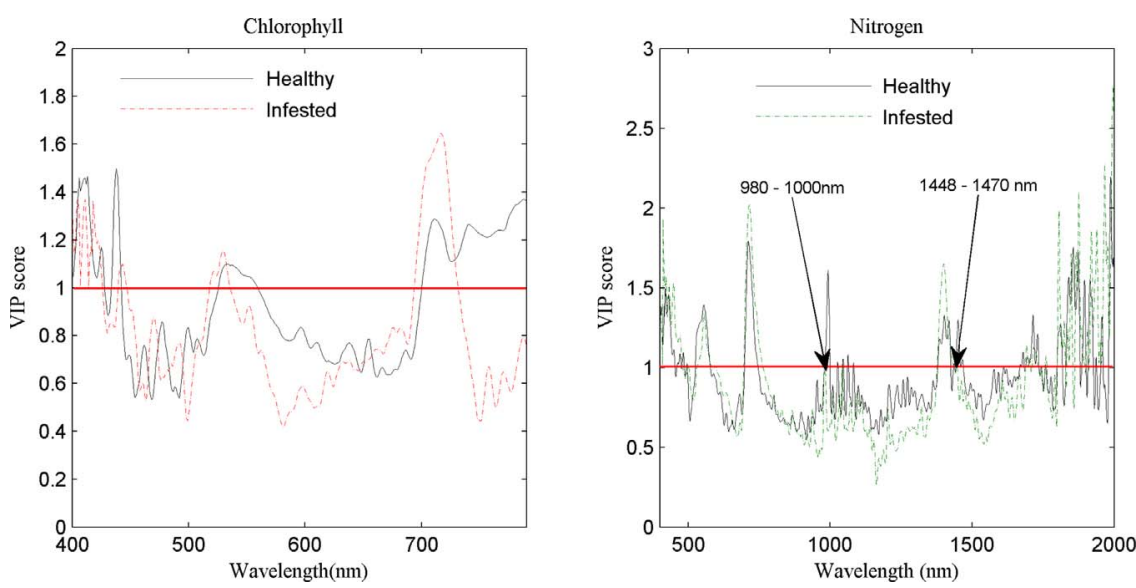

Fig. 7. Importance of wavelengths corresponding to the highest value of variable importance in the projection scores of partial least squares regression in healthy and infested samples, used for chlorophyll and nitrogen estimation. 

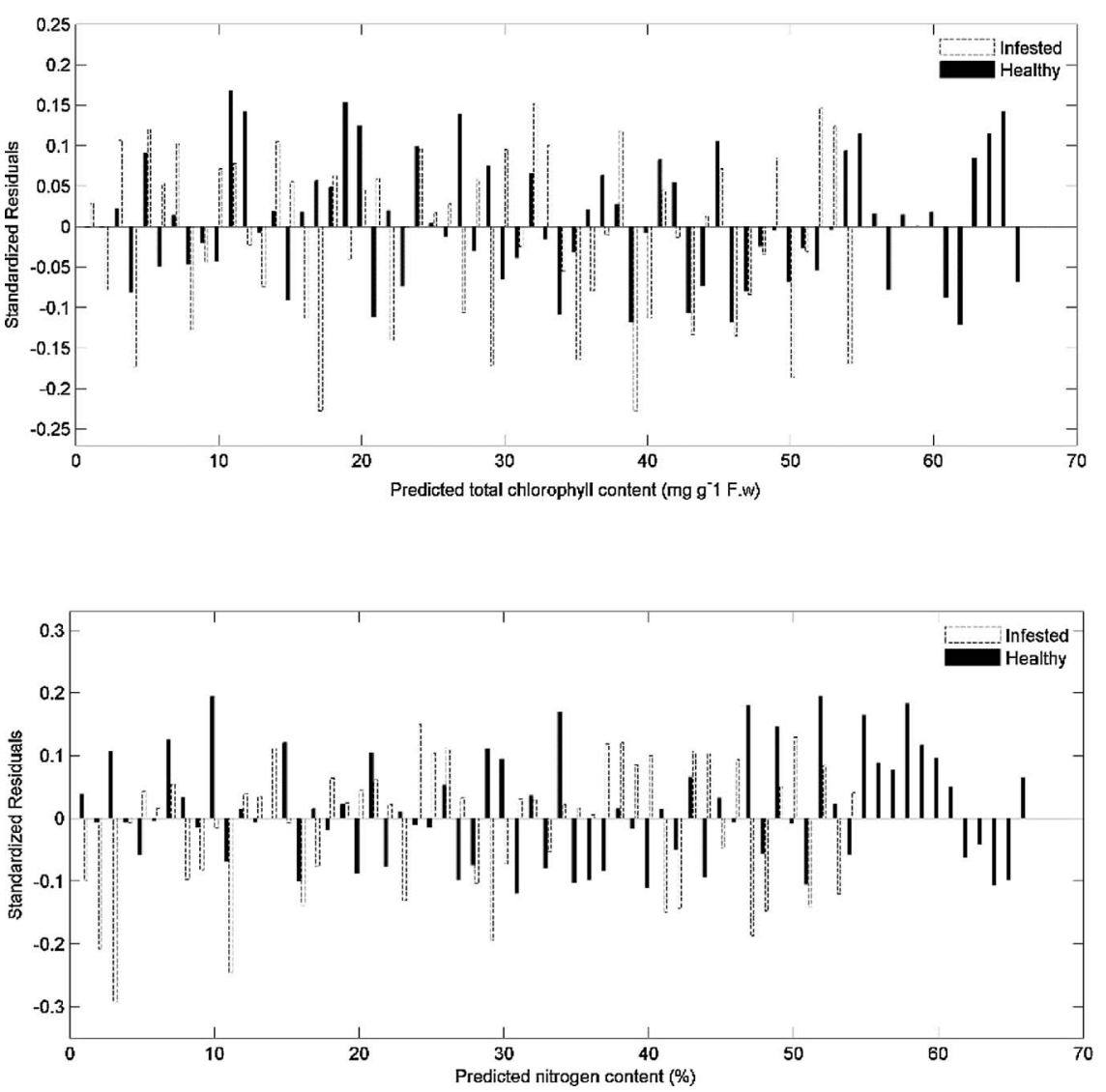

Fig. 8. Standardized residuals of predicted total chlorophyll and nitrogen concentration for healthy and infested samples. of healthy and green attacked samples were also significantly different $(\mathrm{p}<0.05)$ in two short-wave infrared regions $(1430-1500 \mathrm{~nm}$ and 1897-2000 nm) (Fig. 3). The most likely cause for this variation is the low water and nitrogen content in the infested samples (Curran et al., 1992; Mirzaie et al., 2014; Peñuelas and Filella, 1998). Physiological research has shown that the fungi carried by the beetles penetrate the living phloem, hampering the translocation of water, sugar and other nutrients within the bole of the tree (Paine et al., 1997; Rohde et al., 1996; Safranyik et al., 2007; Wermelinger, 2004). Not only are the fungi instrumental in the decline of trees, but they also provide a necessary food source for insects during the infestation period (Runesson, 1991). This leads to a gradual decrease in needle biochemical content and water content. Foster et al. (2017) and Cheng et al. (2010) showed that a number of wavebands in the shortwave infrared region have the potential for the detection of bark beetle infestation at the green attack stage which is in line with our observation. Furthermore, in our study, we have verified that the infested trees had a significantly $(\mathrm{p}<0.05)$ lower nitrogen concentration than that found in the healthy trees.

It should also be noted that we found that infestation at the green attack stage weakened the correlation between chlorophyll and foliar nitrogen concentrations. The correlation dropped from $r=0.68$ to $r=0.57$, which may be partially explained by the reduction in the range of the two parameters (Fig. 4). Furthermore, the correlation between reflectance and both total chlorophyll and foliar nitrogen deteriorated as leaves were stressed by a bark beetle green attack (Fig. 6). The significant correlation (negative) between foliar nitrogen and spectral reflectance at the 700 and $1200 \mathrm{~nm}$ (Fig. 6) is due to high concentrations of foliar nitrogen in healthy needles as they also contain high chlorophyll (and possibly other pigment) concentrations, lowering the reflectance. Under stress, trees tend to break down their pigments (Carter and Knapp, 2001), which probably effects the relationship between nitrogen and reflectance for the infested needles. Therefore, the infestation affects the selection of wavelengths that were most sensitive to the biochemical properties, in particular, the chlorophyll concentration, and their retrieval from spectral reflectance. This is demonstrated in Fig. 7, where distinctively lower VIP scores were observed for the infested samples in the $730-790 \mathrm{~nm}$ spectral region. Consequently, the accuracy of estimation of the two parameters in the infested samples decreased (Table 1). To investigate the effects of bark beetle green attack on the prediction bias for total chlorophyll and foliar nitrogen we have used standardized residuals. In general, as can be seen from Fig. 8, the infestation at the green attack stage caused underestimation of these two biochemical parameters from hyperspectral measurements.

\section{Implications for remote sensing applications}

Our study confirms the importance of hyperspectral measurement as well as foliar biochemical properties (i.e. chlorophyll and nitrogen) for the detection of Ips typographus, L. green attack. An extension of this finding would be to investigate the up-scaling of our findings to the canopy level. However, this forms a challenge as many factors such as logistical and technological aspects may limit the scaling up to the canopy level (Foster et al., 2017; Wulder et al., 2009). One of the critical logistical factors that affect a remotely sensed survey for green attacked trees is the timing of the optimal conditions for image acquisition. In addition, spatial and spectral resolutions play an important role in the studies of bark beetle green attack. However, this limitation may be overcome by utilising a UAV-based application and newly available multispectral satellite data, such as provided by Sentinel-2. In our study, the estimation accuracy of foliar chlorophyll and nitrogen concentration using hyperspectral measurements decreased when the tree was infested by bark beetle green attack. This might be used as an indicator for the efficient landscape-wide detection of bark beetle green attack. It is, however, important to note that retrieval accuracies for the total chlorophyll and foliar nitrogen concentrations at the leaf level 
would probably be different from those at the canopy level, because structural and external factors such as illumination and atmospheric conditions may affect the reflectance spectra at the canopy level. Additionally, we found that the wavelength region between 730 and $790 \mathrm{~nm}$ (red-edge) is the most informative spectral region regarding variations in chlorophyll concentration due to bark beetle green attack (Fig. 6). This portion of the spectrum can be found in new multispectral satellites such as Sentinel-2, World View-2 \& 3 RapidEye and therefore it might be possible to scaling up our findings to the canopy level, particularly considering the high spectral and spatial resolution data. Further investigation will show how accurate green attack stages can be detected with different air and spaceborne sensors.

\section{Conclusion}

This study demonstrates that reflectance properties of healthy and green attached Norway spruce trees are significantly different in 917 wavebands between 400 and $2000 \mathrm{~nm}$. We also observed differences in the biochemical properties chlorophyll and nitrogen between healthy and green attacked needles by the bark beetle (Ips typographus, L.). Furthermore, the results demonstrated that the relationship between reflectance and both chlorophyll and nitrogen deteriorated as the leaves became stressed by a bark beetle green attack. Such an infestation affected the estimation accuracy of chlorophyll and nitrogen concentrations, examined using PLSR and hyperspectral reflectance data. The research findings indicate that hyperspectral measurements are promising, and present a powerful tool to determine the damage caused by bark beetle green attack at the leaf level. Further research is required to assess whether or not, the findings of the current study can be verified at the canopy level using different remote sensing data.

\section{Acknowledgments}

This research received financial support from the EU Erasmus Mundus Salam-2 and was co-funded by Natural Resources Department, Faculty of Geo-Information Science and Earth Observation (ITC), University of Twente, the Netherlands. Thanks also go to the Bavarian Forest National Park staff for approving access to the test site and providing field and camping facilities. The authors extend their appreciation for the great support during the laboratory measurements from the GeoScience Laboratory at ITC Faculty, University of Twente. We would like to thank Michal Daszykowski for helpful advice about TOMCAT toolbox.

\section{References}

Ahern, F., 1988. The effects of bark beetle stress on the foliar spectral reflectance of lodgepole pine. Int. J. Remote Sens. 9 (9), 1451-1468.

Ali, A.M., Darvishzadeh, R., Skidmore, A.K., Duren I. v. Heiden, U., Heurich, M., 2016. Estimating leaf functional traits by inversion of PROSPECT: assessing leaf dry matter content and specific leaf area in mixed mountainous forest. Int. J. Appl. Earth Obs. Geoinf. 45, 66-76.

Atzberger, C., Werner, W., 1998. Needle reflectance of healthy and diseased Spruce stands. 1st EARSeL Workshop on Imaging Spectroscopy pp. 271-283.

Bässler, C., Förster, B., Moning Müller, C.J., 2008. The BIOKLIM-Project: Biodiversity Research Between Climate Change and Wilding in a Temperate Montane Forest- the Conceptual Framework.

Bentz, B., Endreson, D., 2003. Evaluating satellite imagery for estimating mountain pine beetle-caused lodgepole pine mortality: current status. In: Mountain Pine Beetle Symposium: Challenges and Solutions. Kelowna, British Columbia. pp. pp. 154-163 (Natural Resources Canada, Canadian Forest Service, Pacific Forestry Centre).

Bentz, B.J., Régnière, J., Fettig, C.J., Hansen, E.M., Hayes, J.L., Hicke, J.A., Kelsey, R.G., Negrón, J.F., Seybold, S.J., 2010. Climate change and bark beetles of the western United States and Canada: direct and indirect effects. Bioscience 60 (8), 602-613.

Beudert, B., Bässler, C., Thorn, S., Noss, R., Schröder, B., Dieffenbach-Fries, H., Foullois, N., Müller, J., 2015. Bark beetles increase biodiversity while maintaining drinking water quality. Conserv. Lett. 8 (4), 272-281.

Bright, B.C., Hicke, J.A., Meddens, A.J.H., 2013. Effects of bark beetle-caused tree mortality on biogeochemical and biogeophysical MODIS products. J. Geophys. Res.: Biogeosci. 118 (3), 974-982.

Cailleret, M., Heurich, M., Bugmann, H., 2014. Reduction in browsing intensity may not compensate climate change effects on tree species composition in the Bavarian Forest National Park. For. Ecol. Manage. 328 (Supplement C), 179-192.

Carrascal, L.M., Galván, I., Gordo, O., 2009. Partial least squares regression as an alternative to current regression methods used in ecology. Oikos 118 (5), 681-690.

Carter, G.A., Knapp, A.K., 2001. Leaf optical properties in higher plants: linking spectral characteristics to stress and chlorophyll concentration. Am. J. Bot. 88 (4), 677-684.

Carter, G.A., Seal, M.R., Haley, T., 1998. Airborne detection of southern pine beetle damage using key spectral bands. Can. J. For. Res. 28 (7), 1040-1045.

Carter, G.A., 1993. Responses of leaf spectral reflectance to plant stress. Am. J. Bot. 239-243.

Cheng, T., Rivard, B., Sánchez-Azofeifa, G.A., Feng, J., Calvo-Polanco, M., 2010. Continuous wavelet analysis for the detection of green attack damage due to mountain pine beetle infestation. Remote Sens. Environ. 114 (4), 899-910.

Chong, I.-G., Jun, C.-H., 2005. Performance of some variable selection methods when multicollinearity is present. Chemom. Intell. Lab. Syst. 78 (1-2), 103-112.

Christiansen, E., Bakke, A., 1988. The spruce bark beetle of eurasia. In: Berryman, A.A. (Ed.), Dynamics of Forest Insect Populations: Patterns, Causes, Implications. Springer US, Boston, MA, pp. pp. 479-503.

Coulson, R.N., Amman, G.D., Dahlsten, D.L., DeMars Jr, , Stephen, C.F., 1985. Forest-bark beetle interactions: bark beetle population dynamics. Integrated Pest Management in Pine-Bark Beetle Ecosystems. John Wiley \& Sons, New York, pp. 61-80.

Curran, P.J., Dungan, J.L., Macler, B.A., Plummer, S.E., Peterson, D.L., 1992. Reflectance spectroscopy of fresh whole leaves for the estimation of chemical concentration. Remote Sens. Environ. 39 (2), 153-166.

Curran, P.J., 1989. Remote sensing of foliar chemistry. Remote Sens. Environ. 30 (3), $271-278$.

Darvishzadeh, R., Skidmore, A., Schlerf, M., Atzberger, C., 2008. Inversion of a radiative transfer model for estimating vegetation LAI and chlorophyll in a heterogeneous grassland. Remote Sens. Environ. 112 (5), 2592-2604.

Daszykowski, M., Serneels, S., Kaczmarek, K., Van Espen, P., Croux, C., Walczak, B., 2007. TOMCAT: A MATLAB toolbox for multivariate calibration techniques. Chemom. Intell. Lab. Syst. 85 (2), 269-277.

Daughtry, C., Biehl, L., Ranson, K., 1989. A new technique to measure the spectral properties of conifer needles. Remote Sens. Environ. 27 (1), 81-91.

Demetriades-Shah, T.H., Steven, M.D., Clark, J.A., 1990. High resolution derivative spectra in remote sensing. Remote Sens. Environ. 33 (1), 55-64.

Deshayes, M., Guyon, D., Jeanjean, H., Stach, N., Jolly, A., Hagolle, O., 2006. The contribution of remote sensing to the assessment of drought effects in forest ecosystems. Ann. For. Sci. 63 (6), 579-595.

Dye, M., Mutanga, O., Ismail, R., 2008. Detecting the severity of woodwasp, Sirex noctilio, infestation in a pine plantation in KwaZulu-Natal, South Africa, using texture measures calculated from high spatial resolution imagery. Afr. Entomol. 16 (2), 263-275.

Eitel, J.U.H., Vierling, L.A., Litvak, M.E., Long, D.S., Schulthess, U., Ager, A.A., Krofcheck, D.J., Stoscheck, L., 2011. Broadband, red-edge information from satellites improves early stress detection in a New Mexico conifer woodland. Remote Sens. Environ. 115 (12), 3640-3646.

Fahse, L., Heurich, M., 2011. Simulation and analysis of outbreaks of bark beetle infestations and their management at the stand level. Ecol. Modell. 222 (11), 1833-1846.

Farrés, M., Platikanov, S., Tsakovski, S., Tauler, R., 2015. Comparison of the variable importance in projection (VIP) and of the selectivity ratio (SR) methods for variable selection and interpretation. J. Chemom. 29 (10), 528-536.

Feret, J.-B., François, C., Asner, G.P., Gitelson, A.A., Martin, R.E., Bidel, L.P.R., Ustin, S.L., le Maire, G., Jacquemoud, S., 2008. PROSPECT-4 and 5: Advances in the leaf optical properties model separating photosynthetic pigments. Remote Sens. Environ. 112 (6), 3030-3043.

Filchev, L., 2012. An assessment of european spruce bark beetle infestation using WorldView-2 Satellite data. In: Proceedings of 1st European SCGIS Conference with International Participation-Best Practices: Application of GIS Technologies for Conservation of Natural and Cultural Heritage Sites (SCGIS-Bulgaria, Sofia). Sofia, Bulgaria. pp. pp. 21-23.

Foster, A.C., Walter, J.A., Shugart, H.H., Sibold, J., Negron, J., 2017. Spectral evidence of early-stage spruce beetle infestation in Engelmann spruce. For. Ecol. Manage. 384, 347-357.

Franklin, S., Wulder, M., Skakun, R., Carroll, A., 2003. Mountain pine beetle red-attack forest damage classification using stratified Landsat TM data in British Columbia Photogrammetric Canada. Eng. Remote Sens. 69 (3), 283-288.

Geladi, P., Kowalski, B.R., 1986. Partial least-squares regression: a tutorial. Anal. Chim. Acta 185, 1-17.

Gimbarzevsky, P., Dawson, A.F., Van Sickle, G.A., 1992. Assessment of Aerial Photographs and Multi-spectral Scanner Imagery for Measuring Mountain Pine Beetle Damage. pp. 333.

Goheen, D., Hansen, E., 1993. Effects of pathogens and bark beetles on forests. In: Filip, T.S.G. (Ed.), Beetle Pathogen Interactions in Conifer Forests. Academic Press, London, pp. 175-196.

Hais, M., Kučera, T., 2008. Surface temperature change of spruce forest as a result of bark beetle attack: remote sensing and GIS approach. Eur. J. For. Res. 127 (4), 327-336.

Heath, J., 2001. The Detection of Mountain Pine Beetle Green Attacked Lodgepole Pine Using Compact Airborne Spectrographic Imager (CASI) Data. University of British Columbia, Vancouver, BC, Canada, pp. 1-72 pp.

Heinze, M., Fiedler, H.J., 1976. Beziehungen des chlorophyllgehaltes zu standortsfaktoren, ernährungszustand und wachstum bei koniferen. Flora 165 (3), 269-293.

Heurich, M., Beudert, B., Rall, H., Křenová, Z., 2010a. national parks as model regions for interdisciplinary long-term ecological research: the bavarian forest and šumavá national parks underway to transboundary ecosystem research. Long-Term Ecological 
Research. Springer, pp. pp. 327-344.

Heurich, M., Ochs, T., Andresen, T., Schneider, T., 2010b. Object-orientated image analysis for the semi-automatic detection of dead trees following a spruce bark beetle (Ips typographus) outbreak. Eur. J. For. Res. 129 (3), 313-324.

Holm, S., 1979. A simple sequentially rejective multiple test procedure. Scand. J. Stat. 65-70.

Immitzer, M., Atzberger, C., 2014. Early detection of bark beetle infestation in Norway spruce (Picea abies, L.) using worldView-2 data frühzeitige erkennung von borkenkä ferbefall an fichten mittels worldView-2 satellitendaten. Photogramm. Fernerk. Geoinf. 2014 (5), 351-367.

Ismail, R., Mutanga, O., 2010. A comparison of regression tree ensembles: predicting Sirex noctilio induced water stress in Pinus patula forests of KwaZulu-Natal, South Africa. Int. J. Appl. Earth Obs. Geoinf. 12, S45-S51.

Jensen, J.R., 2009. Remote Sensing of the Environment: an Earth Resource Perspective 2/ e. Pearson Education, India.

Klein, W.H., 1973. Beetle-killed pine estimates. Photogramm. Eng. 39 (4).

Kováč, D., Navrátil, M., Malenovský, Z., Štroch, M., Špunda, V., Urban, O., 2012. Reflectance continuum removal spectral index tracking the xanthophyll cycle photoprotective reactions in Norway spruce needles. Funct. Plant Biol. 39 (12), 987.

Kurz, W.A., Dymond, C.C., Stinson, G., Rampley, G.J., Neilson, E.T., Carroll, A.L., Ebata, T., Safranyik, L., 2008. Mountain pine beetle and forest carbon feedback to climate change. Nature 452 (7190), 987-990.

Latifi, H., Schumann, B., Kautz, M., Dech, S., 2014. Spatial characterization of bark beetle infestations by a multidate synergy of SPOT and Landsat imagery. Environ. Monit. Assess. 186 (1), 441-456.

Lausch, A., Heurich, M., Fahse, L., 2013. Spatio-temporal infestation patterns of ips typographus (L.) in the bavarian forest national park, Germany. Ecol. Indic. 31, 73-81.

Lawrence, R., Labus, M., 2003. Early detection of Douglas-fir beetle infestation with subcanopy resolution hyperspectral imagery. West. J. Appl. For. 18 (3), 202-206.

Lehnert, L.W., Bässler, C., Brandl, R., Burton, P.J., Müller, J., 2013. Conservation value of forests attacked by bark beetles: highest number of indicator species is found in early successional stages. J. Nat. Conserv. 21 (2), 97-104.

Li, H., Xu, Q., Liang, Y., 2014. libPLS: an integrated library for partial least squares regression and discriminant analysis. PeerJ PrePrints 2 (e190v1).

Lichtenthaler, H.K., 1987. Chlorophylls and carotenoids: pigments of photosynthetic biomembranes. Methods Enzymol. 148, 350-382.

Lindenmayer, D., Franklin, J.F., 2002. Conserving Forest Biodiversity: a Comprehensive Multiscaled Approach. Island Press.

Lobinger, G., 1994. Air temperature as a limiting factor for flight activity of two species of pine bark beetles, Ips typographus L. and Pityogenes chalcographus L (Col., Scolytidae). Anzeiger für Schädlingskunde, Pflanzenschutz, Umweltschutz 67 (1), 14-17.

Lottering, R., Mutanga, O., Peerbhay, K., 2016. Detecting and mapping levels of Gonipterus scutellatus-induced vegetation defoliation and leaf area index using spatially optimized vegetation indices. Geocarto Int. 1-16.

Müller, J., Bußler, H., Goßner, M., Rettelbach, T., Duelli, P., 2008. The European spruce bark beetle Ips typographus in a national park: from pest to keystone species. Biodivers. Conserv. 17 (12), 2979-3001.

Malenovský, Z., Albrechtová, J., Lhotáková, Z., Zurita-Milla, R., Clevers, J., Schaepman, M., Cudlín, P., 2006. Applicability of the PROSPECT model for Norway spruce needles. Int. J. Remote Sens. 27 (24), 5315-5340.

Marx, A., an der Havel, B., 2010. Erkennung von borkenkäferbefall in fichtenreinbeständen mit multi-temporalen rapideye-satellitenbildern und datamining-techniken. Photogramm. Fernerk. Geoinf. 4, 243-252.

Meddens, A.J.H., Hicke, J.A., Vierling, L.A., Hudak, A.T., 2013. Evaluating methods to detect bark beetle-caused tree mortality using single-date and multi-date Landsat imagery. Remote Sens. Environ. 132, 49-58.

Meddens, A.J., 2012. Mapping and Detecting Bark Beetle-caused Tree Mortality in the Western United States. Dissertation Abstracts International, University of Idaho (AAT 3524572 Thesis).

Mesarch, M.A., Walter-Shea, E.A., Asner, G.P., Middleton, E.M., Chan, S.S., 1999. A revised measurement methodology for conifer needles spectral optical properties: evaluating the influence of gaps between elements. Remote Sens. Environ. 68 (2), 177-192.

Mikkelson, K.M., Bearup, L.A., Maxwell, R.M., Stednick, J.D., McCray, J.E., Sharp, J.O., 2013. Bark beetle infestation impacts on nutrient cycling, water quality and interdependent hydrological effects. Biogeochemistry 115 (1-3), 1-21.

Miller, Wu, J.Y., Boyer, M.G., Belanger, M., Hare, E.W., 1991. Seasonal patterns in leaf reflectance red-edge characteristics. Int. J. Remote Sens. 12 (7), 1509-1523.

Mirzaie, M., Darvishzadeh, R., Shakiba, A., Matkan, A.A., Atzberger, C., Skidmore, A., 2014. Comparative analysis of different uni- and multi-variate methods for estimation of vegetation water content using hyper-spectral measurements. Int. J. Appl. Earth Obs. Geoinf. 26, 1-11.

Murtha, P., Wiart, R., 1989. PC-based digital analysis of mountain pine beetle currentattacked and non-attacked lodgepole pine. Can. J. Remote Sens.

Murtha, P.A., 1972. A Guide to Air Photo Interpretation of Forest Damage in Canada vi Canadian Forestry Service, Ottawa Publication (Canadian Forestry Service); no. 1292, 63 p.

Murtha, P.A., 1978. Remote sensing and vegetation damage: a theory for detection and assessment. Photogramm. Eng. Remote Sens. 44 (9).

Näsi, R., Honkavaara, E., Lyytikäinen-Saarenmaa, P., Blomqvist, M., Litkey, P., Hakala, T., Viljanen, N., Kantola, T., Tanhuanpää, T., Holopainen, M., 2015. Using UAV-based photogrammetry and hyperspectral imaging for mapping bark beetle damage at treelevel. Remote Sens. 7 (12), 15467-15493.

Nicolaï, B.M., Beullens, K., Bobelyn, E., Peirs, A., Saeys, W., Theron, K.I., Lammertyn, J., 2007. Nondestructive measurement of fruit and vegetable quality by means of NIR spectroscopy: a review. Postharvest Biol. Technol. 46 (2), 99-118.

Niemann, K.O., Visintini, F., 2005. Assessment of potential for remote sensing detection of bark beetle-infested areas during green attack: a literature review. Natural Resources Canada. Canadian Forest Service, pp. pp. 1-14.

Niemann, K.O., Quinn, G., Stephen, R., Visintini, F., Parton, D., 2015. Hyperspectral remote sensing of mountain pine beetle with an emphasis on previsual assessment. Can. J. Remote Sens. 41 (3), 191-202.

Nikolov, C., Konôpka, B., Kajba, M., Galko, J., Kunca, A., Janský, L., 2014. Post-disaster forest management and bark beetle outbreak in tatra national park, Slovakia. Mt. Res. Dev. 34 (4), 326-335.

Ortiz, S., Breidenbach, J., Kändler, G., 2013. Early detection of bark beetle green attack using terraSAR-X and RapidEye data. Remote Sens. 5 (4), 1912-1931.

Paine, T., Raffa, K., Harrington, T., 1997. Interactions among scolytid bark beetles, their associated fungi, and live host conifers. Annu. Rev. Entomol. 42 (1), 179-206.

Peñuelas, J., Filella, I., 1998. Visible and near-infrared reflectance techniques for diagnosing plant physiological status. Trends Plant Sci. 3 (4), 151-156.

Peterson, D.L., Aber, J.D., Matson, P.A., Card, D.H., Swanberg, N., Wessman, C., Spanner, M., 1988. Imaging SpectrometryRemote sensing of forest canopy and leaf biochemical contents. Remote Sens. Environ. 24 (1), 85-108.

Pfeifer, E.M., Hicke, J.A., Meddens, A.J., 2011. Observations and modeling of aboveground tree carbon stocks and fluxes following a bark beetle outbreak in the western United States. Global Change Biol. 17 (1), 339-350.

Raffa, K.F., Aukema, B.H., Bentz, B.J., Carroll, A.L., Hicke, J.A., Turner, M.G., Romme, W.H., 2008. Cross-scale drivers of natural disturbances prone to anthropogenic amplification: the dynamics of bark beetle eruptions. Bioscience 58 (6), 501-517.

Reid, R., 1961. Moisture changes in lodgepole pine before and after attack by the mountain pine beetle. For. Chron. 37 (4), 368-375.

Rohde, M., Waldmann, R., Lunderstädt, J., 1996. Induced defence reaction in the phloem of spruce (Picea abies) and larch (Larix decidua) after attack by Ips typographus and Ips cembrae. For. Ecol. Manage. 86 (1), 51-59.

Runesson, U.T., 1991. Considerations for Early Remote Detection of Mountain Pine Beetle in Green-foliaged Lodgepole Pine. University of British Columbia.

Safranyik, L., Carroll, A.L., Wilson, B., 2007. The biology and epidemiology of the mountain pine beetle in lodgepole pine forests. The Mountain Pine Beetle: a Synthesis of Biology, Management and Impacts on Lodgepole Pine. pp. 3-66.

Savitzky, A., Golay, M.J., 1964. Smoothing and differentiation of data by simplified least squares procedures. Anal. Chem. 36 (8), 1627-1639.

Schmidt, K.S., Skidmore, A.K., 2003. Spectral discrimination of vegetation types in a coastal wetland. Remote Sens. Environ. 85 (1), 92-108.

Schneider, C.A., Rasband, W.S., Eliceiri, K.W., 2012. NIH Image to ImageJ: 25 years of image analysis. Nat. Meth. 9 (7), 671-675.

Schowalter, T.D., 2012. Ecology and management of bark beetles (Coleoptera: curculionidae: scolytinae) in southern pine forests. J. Integr. Pest Manage. 3 (2), 1-7.

Seidl, R., Schelhaas, M.-J., Lexer, M.J., 2011. Unraveling the drivers of intensifying forest disturbance regimes in Europe. Global Change Biol. 17 (9), 2842-2852.

Seidl, R., Schelhaas, M.-J., Rammer, W., Verkerk, P.J., 2014. Increasing forest disturbances in Europe and their impact on carbon storage. Nat. Clim. Change 4 (9), $806-810$.

Simard, M., Powell, E.N., Raffa, K.F., Turner, M.G., 2012. What explains landscape patterns of tree mortality caused by bark beetle outbreaks in Greater Yellowstone? Global Ecol. Biogeogr. 21 (5), 556-567.

Skakun, R.S., Wulder, M.A., Franklin, S.E., 2003. Sensitivity of the thematic mapper enhanced wetness difference index to detect mountain pine beetle red-attack damage. Remote Sens. Environ. 86 (4), 433-443.

Slaton, M.R., Hunt, E.R., Smith, W.K., 2001. Estimating near-infrared leaf reflectance from leaf structural characteristics. Am. J. Bot. 88 (2), 278-284.

Smith, K., Steven, M., Colls, J., 2004. Use of hyperspectral derivative ratios in the rededge region to identify plant stress responses to gas leaks. Remote Sens. Environ. 92 (2), 207-217.

Sprintsin, M., Chen, J.M., Czurylowicz, P., 2011. Combining land surface temperature and shortwave infrared reflectance for early detection of mountain pine beetle infestations in western Canada. J. Appl. Remote Sens. 5 (1).

Tenenhaus, M., 1998. La régression PLS. edition TECHNIP, Paris.

Thom, D., Seidl, R., 2015. Natural disturbance impacts on ecosystem services and biodiversity in temperate and boreal forests. Biol. Rev.

Vanderhoof, M., Williams, C.A., Ghimire, B., Rogan, J., 2013. Impact of mountain pine beetle outbreaks on forest albedo and radiative forcing, as derived from Moderate Resolution Imaging Spectroradiometer, Rocky Mountains, USA. J. Geophys. Res.: Biogeosci. 118 (4), 1461-1471.

Verbesselt, J., Robinson, A., Stone, C., Culvenor, D., 2009. Forecasting tree mortality using change metrics derived from MODIS satellite data. For. Ecol. Manage. 258 (7), 1166-1173.

Wang, Z., Skidmore, A.K., Darvishzadeh, R., Heiden, U., Heurich, M., Wang, T., 2015a. Leaf nitrogen content indirectly estimated by leaf traits derived from the PROSPECT model. IEEE J. Sel. Top. Appl. Earth Obs. Remote Sens. 8 (6), 3172-3182.

Wang, Z., Skidmore, A.K., Wang, T., Darvishzadeh, R., Hearne, J., 2015b. Applicability of the PROSPECT model for estimating protein and cellulose + lignin in fresh leaves. Remote Sens. Environ. 168, 205-218.

Waring, K.M., Reboletti, D.M., Mork, L.A., Huang, C.-H., Hofstetter, R.W., Garcia, A.M., Fulé, P.Z., Davis, T.S., 2009. Modeling the impacts of two bark beetle species under a warming climate in the southwestern USA: ecological and economic consequences. Environ. Manage. 44 (4), 824-835.

Wermelinger, B., 2004. Ecology and management of the spruce bark beetle Ips typographus-a review of recent research. For. Ecol. Manage. 202 (1-3), 67-82.

Wold, S., Johansson, E., Cocchi, M., 1993. PLS-partial least squares projections to latent structures. 3D QSAR in Drug Design 1. pp. 523-550. 
Wold, S., Sjöström, M., Eriksson, L., 2001. PLS-regression: a basic tool of chemometrics. Chemom. Intell. Lab. Syst. 58 (2), 109-130.

Wulder, M.A., White, J., Bentz, B., Alvarez, M., Coops, N., 2006. Estimating the probability of mountain pine beetle red-attack damage. Remote Sens. Environ. 101 (2), 150-166.

Wulder, M.A., White, J.C., Carroll, A.L., Coops, N.C., 2009. Challenges for the operational detection of mountain pine beetle green attack with remote sensing. For. Chron. 85 (1), 32-38.

Xu, Q.-S., Liang, Y.-Z., 2001. Monte carlo cross validation. Chemom. Intell. Lab. Syst. 56 (1), 1-11.

Yamaoka, Y., Swanson, R., Hiratsuka, Y., 1990. Inoculation of lodgepole pine with four blue-stain fungi associated with mountain pine beetle, monitored by a heat pulse velocity (HPV) instrument. Can. J. For. Res. 20 (1), 31-36.

Yoder, B.J., Pettigrew-Crosby, R.E., 1995. Predicting nitrogen and chlorophyll content and concentrations from reflectance spectra $(400-2500 \mathrm{~nm})$ at leaf and canopy scales. Remote Sens. Environ. 53 (3), 199-211.
Zarco-Tejada, P., Sepulcre-Cantó, G., 2007. Remote sensing of vegetation biophysical parameters for detecting stress condition and land cover changes. Estudios de la Zona no Saturada del Suelo VIII, 37-44.

Zeppenfeld, T., Svoboda, M., DeRose, R.J., Heurich, M., Müller, J., Čížková, P., Starý, M., Bače, R., Donato, D.C., Bugmann, H., 2015. Response of mountainPicea abiesforests to stand-replacing bark beetle outbreaks: neighbourhood effects lead to self-replacement. J. Appl. Ecol. 52 (5), 1402-1411.

Zhang, Y., Chen, J.M., Miller, J.R., Noland, T.L., 2008. Leaf chlorophyll content retrieval from airborne hyperspectral remote sensing imagery. Remote Sens. Environ. 112 (7), 3234-3247.

Zhang, C., Liu, Y., Kovacs, J.M., Flores-Verdugo, F., de Santiago, F.F., Chen, K., 2012. Spectral response to varying levels of leaf pigments collected from a degraded mangrove forest. J. Appl. Remote Sens. 6 (1).

van Maarschalkerweerd, M., Husted, S., 2015. Recent developments in fast spectroscopy for plant mineral analysis. Front. Plant Sci. 6. 